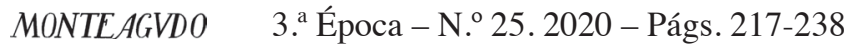

\title{
El ESPACIO NOVELESCO Y LA DESCRIPCIÓN EN BELTENEBROS, de Antonio Muñoz Molina
}

\author{
MAdiAn MAGHRABI
}

Universidad de Aswan

\section{RESUMEN:}

La presente investigación consiste en el análisis del espacio novelesco y la descripción en Beltenebros (1985). Por un lado, se hará hincapié sobre el tipo de espacio, su función y su correlación con los personajes de la novela, destacando los que adquieren especial relevancia en los hechos narrados. Por otro lado, se analiza la descripción, como uno de los procedimientos narrativos, y su función en el discurso narrativo. En este punto, es interesante subrayar la forma cinematográfica y los elementos sensoriales que emplea el escritor a la hora de describir, minuciosamente, objetos y ambientes con el fin de crear una atmósfera de suspense e intriga hasta poner el punto final de su obra.

\section{PALABRAS CLAVE:}

Antonio Muñoz Molina, espacio, descripción, novela policiaca.

\begin{abstract}
:
The present study consists in the analysis of the fictional space and the description in Beltenebros (1985). On the one hand, emphasis will be placed on the type of space, its function and its correlation with the characters of the novel, highlighting those that acquire special relevance in the narrated events. On the other hand, the description is analyzed, as one of the narrative procedures, and its function in the narrative discourse. At this point, it is interesting to underline the cinematographic form and the sensorial elements that the writer uses when describing, meticulously, objects and environments with the purpose of creating an atmosphere of suspense and intrigue until putting the end point of his work.
\end{abstract}

\section{KEYWORDS:}

Antonio Muñoz Molina, space, description, police novel.

\section{Introducción}

Es de suma importancia señalar la enorme trascendencia que ha adquirido el espacio narrativo como uno de los elementos de la obra literaria. Es el componente narrativo que se refiere al lugar en el que se desarrolla la acción y por el que se mueven los personajes. De tal modo que los personajes no pueden prescindir del espacio porque es el lugar donde transitan y se relacionan con otros. Asimismo, el espacio es considerado como la columna vertebral por unir los elementos de la novela entre sí. 
En muchas obras los autores utilizan, como protagonista de sus novelas, el espacio narrativo de un pueblo, una ciudad o un edificio.

En cuanto a los tipos del espacio narrativo destacan: espacios urbanos, rurales, domésticos, idealizados, abiertos o cerrados, estáticos o móviles. Los espacios abiertos pueden ser avenidas, calles, paseos etc. En cambio, los espacios cerrados pueden ser cualquier sitio rodeado de cuatro paredes sea una casa particular, un bar o una habitación. Esta tipología la aplicaremos, más adelante, en la presente investigación para definir el tipo de espacio que emplea el autor en su obra objeto de estudio.

Partiendo de la importancia que tiene el espacio en la narración, he visto que es recomendable en la presente investigación hacer hincapié en la descripción y sus funciones en esta novela. Por ello, dedico una pequeña síntesis de las opiniones de algunos teóricos sobre dicha cuestión. Desde el punto de vista de Garrido Domínguez, «La descripción o topografía es la denominación convencional del discurso del espacio. A través de ella el relato se dota de una geografía, una localización para la acción narrativa» (1993: 218). Por su parte, Martínez Bonati define la descripción como «representación de aspectos inalterados de las cosas, permanentes, momentáneas o recurrentes, o de hechos sin mayor duración» (Castagnino, 1969: 174).

En la misma línea, a pesar de la contribución de la descripción en la estructura de la obra narrativa, también cabe destacar su papel en ralentizar el ritmo de la narración. Para Jean Ricardou, «la descripción suspende la corriente de las acciones» (1967: 67). Por su parte, Genette señala que «todo relato se compone [...] de representaciones, de acciones y acontecimientos que constituyen la narración y de representaciones de objetos o personajes que llamamos hoy día la descripción» (1972: 52). En cuanto a la importancia de la descripción como elemento esencial en la estructura narrativa, Philipe Hamon llega a puntualizar que, «Toda descripción se presenta, pues, como un conjunto léxico metonímicamente homogéneo en el que la extensión está ligada al vocabulario disponible por el autor» (1972: 465).

En cuanto a Beltenebros ${ }^{1}$, que pertenece al género policiaco, está estructurada en dieciocho capítulos en los que se narra la historia del capitán Darman, uno de los miembros de un grupo antifranquista, encargado de viajar a Madrid para asesinar a Andrade, un supuesto traidor de esta organización. De tal modo, Madrid será el espacio narrativo donde transcurre una gran parte de los episodios. Los hechos transcurren durante dos días, desde la llegada de Darman al aeropuerto de Madrid por la tarde hasta el día siguiente por la noche, tras la muerte del comisario Ugarte. En cuanto al tiempo de la historia hay una referencia a la época de la posguerra española, concretamente los años sesenta. La novela tiene como protagonista central

\footnotetext{
${ }^{1}$ Antonio Muñoz Molina, Beltenebros, Barcelona, Seix Barral, 1990. Todas nuestras citas proceden de esta edición.
} 
al capitán Darman, y anti protagonista, el comisario Ugarte. En la novela Antonio Molina narra los hechos a través de un narrador en primera persona que es el protagonista principal de la obra. El mismo escritor hace referencia a esta novela que fue escrita en una etapa de su vida que, anímicamente, era muy difícil de soportar:

Fue una época de negrura. Yo no tenía esperanza ninguna en esa época. Al principio comencé a escribir Beltenebros alterando capítulos en primera persona contados por Darman y otros escritos en tercera persona en los que aparecían otros personajes, pero al final la escribí toda desde el punto de vista de Darman² (Muñoz Molina, 1999: 38).

\section{El espacio novelesco en Beltenebros}

Beltenebros es una novela urbana desarrollada casi íntegramente en Madrid, con referencias aisladas a otras ciudades europeas que forman parte del movimiento de los personajes principales como Milán, Brighton, Calais, París, Berlín, excepto Florencia. En esta ciudad se produce el encuentro de Darman con Bernal para recibir las instrucciones de su segunda misión en la capital española. También son muy abundantes las alusiones a las diferentes calles de Madrid, situadas casi todas ellas en el centro de la ciudad y algunas en los suburbios cercanos a la capital. Pero Madrid, que muestra el escritor español, no fue diferente al de veinte años atrás en la vida del capitán Darman aunque hubo cambios de gobierno, que para el bando contrario fue ilegítimo.

En Beltenebros el escritor español abre el campo geográfico de actuación de los personajes por el centro de Madrid, concretamente muy cerca de la famosa estación de trenes de Atocha y, aunque se mantiene el valor simbólico que puede poseer, en ocasiones el asentamiento de los personajes, sus movimientos hacia otros espacios carecen de relevancia en comparación con los otros.

En la novela analizada, la mayor novedad del espacio se presenta desde el punto de vista de las funciones que desempeña, pues no sólo contribuye a la organización narrativa y es signo del personaje, sino que se convierte en una forma de exposición de relaciones sociológicas, particularmente de las diferencias de clase. Esto se observa en la novela en el lugar reservado para el comisario Ugarte en el local nocturno, la boîte Tabú. Es un sitio privilegiado donde puede ver y controlar a todo el mundo que está en el escenario o alrededor de las mesas en la sala del lugar.

\footnotetext{
${ }^{2}$ El momento histórico y cultural en el que Muñoz Molina desarrolla su actividad literaria fue uno de los motivos de la crisis personal que atravesó el escritor y llegó a reflejarse en su producción literaria (Begines Hormigo, 2006: 262).
} 
En la novela señalamos que hay un espacio para la evocación que es la librería de Darman en Brighton, Inglaterra. Dicho espacio alterna con breves referencias a otros lugares en la misma zona costera, cerca del muelle, como el bar donde solía ir el capitán Darman a tomar algunas cervezas frías y más tarde salir a pasear y contemplar el mar. A partir de allí, las abundantes referencias espaciales no tienen otra función que la de situar los acontecimientos. Antonio Muñoz Molina se limita a localizar a sus personajes en determinados ambientes y describe sus itinerarios. De tal forma, sabemos que Darman va a la boîte Tabú atravesando las calles de Atocha, Antón Martín y Benavente, pasando por la emblemática Puerta del Sol. De esta manera y con la ayuda de algunos cuadros generales Antonio Muñoz Molina va dando a conocer distintos ambientes de la ciudad en la que desarrolla su novela.

En esta novela el espacio novelesco se construye en: espacios abiertos, cerrados y móviles. Entre los que adquieren especial relevancia destacan: la estación de Atocha, la boîte Tabú, Universal Cinema, los aeropuertos y el almacén donde estaba escondido Andrade. Así que el espacio adquiere doble función en esta obra; es a la vez el elemento de contraste con otras zonas urbanas y la expresión del encierro de Andrade. Esta última idea ha sido puesta de manifiesto por Wellek y Warren señalando que, «los interiores domésticos pueden ser vistos como expresiones, metonímicas o metafóricas, del personaje. La casa de un hombre es una extensión de él mismo» (1963: 221).

\subsection{Los espacios abiertos y urbanos de la ciudad de Madrid}

El espacio urbano, en donde la ciudad es el mayor referente de esta temática, es el lugar donde ocurre la novela urbana. Antonio Muñoz Molina sitúa la novela en una ciudad concreta y determinada, Madrid. Casi todos los hechos tienen lugar en ella excepto algunos que ocurren en otras ciudades como Florencia. El espacio es evidentemente urbano, son calles, avenidas, paseos en los cuales actúan los personajes. El escritor concibe la ciudad como un espacio múltiple y variado que abarca a los personajes, los ambientes y los acontecimientos. La elección de la ciudad como un gran espacio urbano tiene un alcance social, puesto que los caracteres de los diferentes espacios de la ciudad determinan los modos de vida de la gente que la pueblan. De tal modo, el ámbito urbano y la presencia de los personajes resultan en tal sentido inseparables; ambos son partes de un mismo mundo ficticio.

En el análisis de esta novela destacan varios aspectos que configuran las variantes en las que se articula la obra objeto del estudio. En primer lugar, el marco urbano aclarado desde las primeras palabras del relato: «Vine a Madrid para matar a un hombre»; se trata siempre de la gran ciudad que determina los pasos de los protagonistas y, dentro de esta gran ciudad, destacan otros, como los barrios desfavorecidos 
donde está situado club nocturno la boîte Tabú. Es una zona de calles estrechas, edificios de ladrillo y pequeñas tiendas de comestibles y casas de huéspedes para viajeros pobres. Estos forman un contraste con algunas pinceladas de lo que puede ser parte rica de la ciudad o las zonas de gente acomodada. De esta forma, el recorrido urbano del protagonista está marcado y se organiza para dar a conocer una puerta de entrada a la gran ciudad, en el caso de Beltenebros, es el aeropuerto de Madrid, la estación de Atocha y el hotel Nacional. De acuerdo con las palabras de Eugenia Popeanga, «Consideramos que la gran ciudad (en términos de R. Barthes) es en realidad uno de los elementos constitutivos de este tipo de literatura» (2009: 293).

Ahora bien, la ciudad de Madrid como espacio urbano y abierto de una novela de intriga y suspense esta mencionada, explícitamente, en más de una ocasión a lo largo de la narración:

Estaba en Madrid, pero era preciso que no quedara tras de mí ninguna señal de mi llegada, que durante uno o dos días mi presencia se disolviera en la ciudad hasta hacerme invisible igual que se disolvía ahora en los laberintos de la terminal, hasta tal punto que cuando busqué mi cara entre las que se reflejaban en las cristaleras de la cafetería no pude encontrarla (Muñoz Molina, 1990: 67).

También es de notar la correlación que encierra el espacio urbano de la ciudad de Madrid con el personaje central de esta novela, que sigue igual que veinte años atrás; es el lugar de los recuerdos. Siempre le atrae a la memoria muchas cosas del pasado y la percibe como secuestrada por unos intrusos y usurpadores «los franquistas». Este punto de vista del protagonista es significativo, porque en la novela la ciudad es considerada como metonimia de España de los años sesenta:

Cada vez que volvía a Madrid era como si perdiese la piel de indiferencia y olvido que el tiempo había agregado a la memoria, y todas las cosas me herían como recién sucedidas, la misma luz del pasado, los raíles de los tranvías brillando después de la lluvia sobre el adoquinado, la estatua blanca de Cibeles. [...]

La misma ciudad por la que yo había transitado en mi juventud y que ya no reconocía. [...] la vida diaria de un país que ya me es ajeno (Muñoz Molina, 1990: 68 y 207).

Como ya indicamos, el espacio de la obra es algo más que un simple reflejo o mímesis de la geografía madrileña. En Beltenebros se encuentra la ciudad de Madrid, tanto en su nivel temporal como en el topográfico. Allí está el Madrid de los años sesenta al se refiere el narrador sin ningún cambio. 
En relación con los espacios abiertos, en la novela tanto en Madrid como otras ciudades europeas, destacan los aeropuertos que aparte de que son considerados como puntos de salida y llegada, también sirven de tránsito para muchas personas. Por ellos transitaba el capitán Darman para recibir instrucciones o cumplir con las misiones encargadas por parte de su organización. Su correlación con dicho personaje se manifiesta en perder hasta la noción del tiempo, como se ilustra en la siguiente cita:

Es verdad que entonces me pasaba la mitad de la vida en los aeropuertos, y como en ellos ni el tiempo ni el espacio son del todo reales, casi nunca sabía exactamente dónde estaba y vivía bajo una tibia y perpetua sensación de provisionalidad y destierro, de tiempo cancelado y espera sin motivo (Muñoz Molina, 1990:14).

En esta novela subrayamos que los aeropuertos son espacios abiertos y urbanos que encierran una correlación trascendental y estrecha vinculación con respecto al capitán Darman. De acuerdo con Antonio Garrido «El espacio nunca es indiferente para el personaje. Las más de las veces el espacio funciona como metonimia o metáfora del personaje [...] el espacio refleja, aclara o justifica el estado anímico del personaje» (1993: 211). Estos espacios representan para el protagonista la falta de identidad, porque en ellos, él llega a perder, de una forma notable, la verdadera noción del espacio y el tiempo. También por culpa de esta sensación, en muchas ocasiones, Darman siente como un extraño y exiliado hasta el punto de pensar que su vida parece a la de un monje, por la simple razón de recluirse en los hoteles y los aeropuertos:

Me pasaba la mitad de mi vida en los aeropuertos y como en ellos ni el tiempo ni el espacio son del todo reales, casi nunca sabía exactamente dónde estaba y vivía bajo una tibia y perpetua sensación de provisionalidad y destierro del tiempo cancelado y espera $\sin$ motivo. [...]

Esta vez no habría nadie esperándome en el aeropuerto de Madrid. [...] Nadie vendría esta vez a esperarme, era preciso que nadie tuviera noticia de mi viaje, ni siquiera los más leales entre los supervivientes. (Muñoz Molina, 1990: 14 y 63)

En la cita anterior se observa que el espacio se hace más denso y pasa de la pura descripción del aeropuerto a la creación de una atmósfera estrechamente vinculada a la personalidad del protagonista. Por la máxima discreción de la misión del capitán Darman, el narrador pretende dejar claro que nadie le espera en Madrid, como en otras ocasiones de sus viaje. A través de la cual se manifiesta la clandestinidad del trabajo y la ideología de la organización. También señalamos que en otras misiones 
Darman frecuentaba aeropuertos menores, porque en ellos el control policial era más liviano, y al anochecer ya no quedaba casi nadie, sólo los empleados que terminaban sus tareas y las limpiadoras.

La estación de Atocha, es otro de los espacios públicos, abiertos y urbanos que tiene una gran importancia dentro de la capital española, por la magnitud del tránsito e intercambio entre muchos barrios de las afueras de Madrid y otros puntos del país. Dicho espacio urbano no es ante todo un «escenario», sino un lugar real, con existencia propia y lleno de vida y movimiento característicos de toda urbe. En la novela, a través de la descripción de esta estación, el escritor pretende reflejar el caos, el abandono, el mal funcionamiento por parte de la administración ferroviaria de la estación de trenes más importante de la capital española. En sus descripciones, en ciertas ocasiones, lo sensorial no se limita, en algunas casos, a la preponderancia de un número relativamente reducido de sensaciones. De manera singular, cuando lo presentado es una escena o un lugar llenos de vida y de movimiento humano, el lenguaje descriptivo suele incluir la totalidad de lo sensorial. Tal es el caso de la presentación de la estación de Atocha de Madrid, en donde van y vienen multitud de personas:

El azul del fondo era más claro y más limpio que el del mar, pero por los andenes y vestíbulos de la estación cundía un desorden desesperado e inmundo, una angustia de trenes perdidos o interminablemente retrasados que ensombrecía los rostros de fatiga y de insomnio y se adhería a las paredes y el suelo como una suciedad de hollín y de grasa no limpiada en muchos años, igual que la negrura de las vigas metálicas más altas [...] No había un sólo lugar en la estación que oliera a humo agrio de tabaco y a ropa sudada y maltratada en las noches de los trenes y en las salas de espera. Pensé con un doble sentimiento de dolor y de huida que ésta ya no era mi patria, y me apresuré a alejarme de la estación como si abandonara un barco condenado al naufragio (Muñoz Molina, 1990: 73-74) .

En esta cita se observa una descripción selectiva que tiene la función de informar al lector el estado lamentable de la estación más importante de la capital española, no sólo en la mala imagen que representa en sí, sino también a nivel organizativo que deja mucho que desear por parte de cualquier viajero. El desorden y los retrasos de los trenes dejan una consecuencia de cansancio e insomnio muy negativa en las personas que frecuentan la estación, sea a diario o de vez en cuando. Este nivel de decadencia de la estación más importante de la capital española, en sí, es un símbolo de la España de posguerra. Hemos dado en cuenta de ello por la forma de cómo se describe la estación de Atocha, dado que las anteriores descripciones revelan la situación socio-económica de la España de aquella época. 
En la novela destaca el embarcadero del Oeste, uno de los espacio evocados por el protagonista; está situado en Brighton, Inglaterra, muy cerca de la zona donde Darman vive y tiene su tienda de libros y grabados antiguos. En este sitio existe una taberna, que se parece al camarote de un barco, al que solía ir Darman por las tardes, después de cerrar su tienda de libros, para desconectar un poco y tomar alguna cervecita. Desde el punto de vista del protagonista, este sitio simboliza la tristeza y melancolía que no ayudan a vivir, incluso afecta anímicamente a las personas, porque parece a un buque abandonado y en él «notaba la violencia del mar bajo la madera que crujía a mi paso. Muy cerca de la orilla el mar ya parecía una alta sima de naufragios, y en las tardes nubladas cobraba un color gris del que decían que invitaba al suicidio» (Muñoz Molina, 1990: 13).

\subsection{Los espacios cerrados y su correlación con los personajes}

En relación con los espacios cerrados, el autor tiene la inclinación por los espacios interiores como elemento de cohesión entre los personajes. Asimismo, los espacios cerrados se centran en los interiores de las viviendas como la cocina, el salón o diferentes cuartos donde habitan, trabajan o están alojados los personajes de la novela, como los del hotel Nacional, entre otros. A lo largo de la narración el escritor español ha presentado varios espacios cerrados, tales como casas, bares y habitaciones dentro de hoteles o casas particulares. Entre los espacios de esta novela destacan: el almacén de Atocha, la boîte Tabú y Universal Cinema.

El almacén de Atocha, es uno de los espacios cerrados y trascendentales en la novela, está situado a los aledaños de la famosa estación de trenes de Atocha en el centro de la capital española. Este lugar representa para el supuesto traidor, Andrade, el único refugio mientras espera la llegada de un enlace de su organización clandestina, que le trae del exterior el dinero y un pasaporte falso para salir de Madrid. A través de la combinación de lo visual y lo auditivo, que ambos constituyen el método adecuado para crear la atmósfera de ciertos lugares, el narrador describe este almacén abandonado y helado de esta manera:

una torre de ladrillo próxima a los raíles de la estación de Atocha donde pasó algunos días esperándome, porque yo era el hombre que le dijeron que vendría, y al principio me esperó disciplinalmente, muerto de frío, supongo, y de aburrimiento y tal vez de terror, sospechando con certidumbre creciente que algo estaba tramando contra él, desvelado en la noche, bajo la única manta que yo encontré luego en la cama, húmeda y áspera [...], oyendo hasta medianoche el eco de los altavoces bajo la bóveda de la estación y el estrépito de los expresos que empezaban a llegar a Madrid antes del amanecer. (Muñoz Molina, 1990: 7) 
La correlación de este espacio narrativo con Andrade, según la información que nos facilita el narrador, fue su único refugio tras su huida de la policía madrileña. Es un lugar abandonado por las malas condiciones que nos presenta el escritor, y a través de la voz narrativa, en primera persona, percibimos lo que representa este sitio y la estrecha vinculación para el supuesto traidor y otros personajes. Aparte de la contaminación acústica, también representa el aburrimiento, el miedo y el terror que percibe Andrade de su organización, aunque está fuera de España. También fue en este sitio donde el capitán Darman encontró una entrada de la boîte Tabú que le lleva a conocer el paradero de Andrade. Igualmente en el almacén se hallaban las novelas sentimentales escritas y firmadas por Rebeca Osorio. De tal modo, se supone que Andrade leía dichos relatos para matar el tiempo en este helado y triste lugar. En el cual la oscuridad es un elemento primordial que constituye la atmósfera de suspense e intriga necesarias para este tipo de narración.

La boîte Tabú, otro de los espacios cerrados de la novela, es un club nocturno convertido en un microespacio de ocio y diversión para muchas personas que solían frecuentar. Referente a su correlación ${ }^{3}$ con los personajes: para Rebeca Osorio es el sitio donde trabaja como bailarina y cantante. Para el comisario Ugarte es el lugar preferido donde tiene un balcón asignado exclusivamente para él. Asimismo, detrás de una cortina roja, él suele vigilar y mirar los bailes y los espectáculos de Rebeca que en algunas noches bailaba y se desnudaba para él, aunque fuese sobre el escenario. Así que, es de notar que el espacio donde se ubica este personaje refleja la jerarquía social y el tipo de trabajo que ejerce. También podemos apuntar que este club nocturno fue el escenario de la muerte del jorobado guardián del local a manos del capitán Darman por impedirle entrar en el único balcón privado y reservado para Ugarte. El narrador describe este sitio, desde el interior, de esta forma:

Sobre cada mesa había una pequeña lámpara azul en forma de paraguas. Brillaban a mi alrededor como velas al fondo de una iglesia. En el escenario, por encima de las cabezas opacas y los rostros azules, cantaba una mujer gorda, con tacones muy altos, con vestido largo de reflejos metálicos que tenía en el costado una abertura singularmente obscena. [...] El pianista parecía un profesor abrumado por una vejez sin dignidad. [...] Yo bebía y escuchaba risas contenidas y murmullos a mi alrededor y me iba envolviendo una lenta sensación de absurdo que agravaban la infamia del alcohol y las sonrisas codiciosas y

\footnotetext{
${ }^{3}$ Con respecto a esta correlación, Bobes Naves señala que el espacio como el tiempo «resulta ser una categoría para el conocimiento, que no se percibe en sí mismo, sino por relación a los objetos que están en él y nos permiten señalar distancias y por relación a los personajes, que se mueven y alternan las relaciones espaciales. Las acciones transcurren en el tiempo, pero los personajes y los objetos se sitúan, estéticamente o dinámicamente, en el espacio» (1993: 174).
} 
adúlteras de los hombres vestidos de oscuro que en las mesas próximas fumaban y bebían junto a mujeres muy pintadas y enredaban como casualmente los dedos en sus manos. [...] Este era tal vez el lugar que había frecuentado Andrade, con corbata, sin duda, con traje oscuro, como casi todos los hombres de su edad intermedia que bebía cerca de mí y se atrevían a tocar con lujuria cobarde las rodillas de las animadoras (Muñoz Molina, 1990: 103-104).

En la descripción del interior de la boîte Tabú, se revela, por medio de ciertos detalles, la artificialidad y lo transitorio de este local nocturno. También en otras descripciones del local, la riqueza sensorial refleja vitalidad y hasta aparecen pinceladas placenteros, como las risas contenidas y sonrisas codiciosas de hombres y mujeres jugueteando.

Como hemos mencionado anteriormente, la boîte Tabú es uno de los espacios cerrados más destacados de la novela. La función simbólica que representa este sitio para los clientes que lo frecuentan, es de evasión, diversión y pasar un tiempo agradable con alguna de las mujeres sentadas en las mesas. En cambio, para la bailarina señorita Osorio es su lugar de trabajo. Pero para el Comisario Ugarte, que lo apodan El Cazador, aparte de que es un lugar donde recabar información, es considerado de dominio y control por las características que definen al palco dentro del local. También en este club destaca el camerino de la señorita Osorio donde suele cambiarse de ropa entre un espectáculo y otro. Este sitio fue testigo de las pocas palabras cruzadas entre ella y Darman con el fin de saber dónde encontrar a Andrade para entregarle el dinero y el pasaporte:

Al final había una puerta cerrada y sobre ella una tarjeta con un nombre escrito a máquina: Srta. Osorio. La abrí y ella estaba de espaldas, sentada frente a un espejo. Pero antes de mirarla a la cara comprendí que cuando lo hiciera ya no la reconocería. [...] -Soy amigo de Andrade- dije-. Le he traído algo de París [...] Tengo su pasaporte y su dinero (Muñoz Molina, 1990: 110 y 113).

Es de notar, que en este el local nocturno, la oscuridad viene a ser el elemento trascendental del espacio perceptible y se opone en forma simbólica a la claridad del ámbito exterior. De tal forma, cada vez que el comisario Ugarte aparece en escena, la atmósfera suele ser producto de falta de luz; la oscuridad simboliza el elemento policiaco y misterioso que representa este hombre. La atmósfera se caracteriza invariablemente por esa misma oscuridad, reveladora de una situación de suspense e intriga.

Universal Cinema o el viejo cine construido en los años treinta, es otro de los espacios estáticos y cerrados de la obra de Molina. En esta novela tiene la función de 
ser el eje estructural de la narración. En este sitio convergen los hilos del relato y se revela la verdad al cabo de veinte años. También es considerado más bien como el antiguo refugio y el lugar de encuentro de la organización antifranquista o la resistencia clandestina. Fue regentado por Walter, jefe de dicha organización en Madrid:

Unos meses antes de que yo llegara, alguien vino a solicitar refugio en el Universal Cinema. Se llamaba Valdivia. Desde 1937 hasta la caída de Madrid había trabajado conmigo en el Servicio de Información Militar (Muñoz Molina, 1990: 130).

En esta novela, Universal Cinema representa una forma de evasión de la realidad, y para la organización antifranquista al que pertenece el capitán Darman y sus compañeros, fue su gran refugio y un lugar de conspiración para llevar a cabo sus planes clandestinos contra sus enemigos, hasta la caída de Madrid en manos de los franquistas. Este sitio, en la oscuridad, fue el escenario de la muerte del comisario Ugarte, cayendo en sus precipicios tras doblarse la barandilla mientras intentaba disparar a Darman.

Es de notar que la importancia del cine como forma de evasión no es un rasgo que distinga a la novela de un autor determinado, sino se convierte en una de las señas de identidad más claras para toda una generación literaria como podemos ver en las palabras pronunciadas por Terenci Moix, «El cine de barrio era una trampa y era droguilla; era hogar, era, pues, un sitio de encuentro, era ateneo del comentario e incluso ágora de la camorra, como se ha visto. Pero fue, sobre todo, un hábito amorosamente mantenido» (1990: 56).

En la novela es destacable la importancia del Universal Cinema y la boîte Tabú como dos espacios empleados por el autor para el tema del doble en la narración. Por ejemplo, el hombre de la espalda retorcida ha trabajado como taquillero en el cine y como portero en el club nocturno. A través de estos dos sitios unidos por un laberinto o túnel secreto, el escritor crea un ambiente de misterio con correlaciones de algunos personajes que se repiten en el tiempo. Por una parte, el personaje de Rebeca Osorio que está más joven en los sesenta que veinte años atrás. Y por otra parte, dos personajes, Walter y Andrade, «que responden al mismo prototipo de traidor y que están enamorados de la misma mujer» (Vázquez Naveira, 2014: 201).

En el mismo sentido, el descubrimiento del túnel que comunica la boîte Tabú con el viejo cine es, a su vez, un laberinto de la memoria que vincula, aparte de dos espacios, también dos tiempos, dos historias paralelas y «en el que la perversión se cifra precisamente en el carácter reiterativo del dolor y del crimen» (Ferrari, 2000: 204).

En esta obra, también destaca el hotel Nacional y dentro del cual está la habitación de Darman que se considera como uno de los espacios cerrados de la novela. 
Este espacio estático y cerrado, con la correlación con los personajes, tiene la función de convertirse en uno de los escenarios del encuentro entre el capitán y Rebeca Osorio. En el mismo sitio, después de interrogarla, llega a la conclusión de que esta mujer fue la que le puso droga en el vaso de whisky que tomó mientras esperaba sentado en el sofá en la casa de Andrade a las afueras de Madrid. Después de quedarse inconsciente y con la señal de encender y apagar la luz dos veces, Andrade sube para recoger el dinero y el pasaporte que le traía Darman. También este sitio fue escenario del encuentro sexual que tuvo Darman con Rebeca Osorio.

En cuanto al hotel Parigi, que es uno de los espacios cerrados de esta novela, está situado en la ciudad de Florencia, donde el capitán Darman estuvo alojado en una de las habitaciones. Dicha habitación era muy estrecha que el narrador la describe de la siguiente manera:

Era una habitación tan alta y tan estrecha que parecía tener sólo dos dimensiones. Me quité la gabardina y el sombrero, me senté en la cama, mirando la maleta cerrada frente a mí. [...] Sin quitarme los zapatos me tendí en la cama, cubriéndome con una colcha fría y más bien rígida, con los ojos cerrados, con la boca tapada por el embozo. [...] Temblaba un poco, tal vez tenía fiebre, y no quería abrir los ojos ni que sonara el teléfono ni salir del hotel. [...] Durante unos minutos, enrarecidos por la fiebre, soñé que estaba en Inglaterra, en mi casa, y que oía el sonido insistente de la campanilla de la tienda (Muñoz Molina, 1990: 25-26).

En las líneas anteriores se ilustra, de todos los objetos allí descritos, la maleta es el que más esclarece la relación entre el capitán Darman y su presencia en este hotel. Por el frío, tal vez, y de las malas condiciones de las instalaciones del hotel, que al parecer no tenía calefacción o por lo menos algo para calentar la habitación, el capitán Darman tuvo fiebre que le obligó a trasladarse desde Italia hasta Inglaterra, soñando con su casa y la campanilla que no dejaba de sonar. En este sentido, LópezLandey señala que al presentar el mundo de los sueños, ensueños y memorias en forma directa, «el novelista puede lograr la creación de un espacio de características tan tangibles como las de aquel en el cual lo observable no pasa de ser lo externo a los personajes » (1979: 34).

La correlación de Darman con este espacio del hotel Parigi en Italia se observa a través de asociar el sonido de una llamada telefónica con el timbre de su tienda que le hacía pensar que quizá alguien venía por un grabado antiguo, recordándole su casa en Brighton. En esta escena observamos la unión entre dos espacios narrativos, dos noches de invierno, el escándalo de la tempestad del mar y el silencio de la nieve. También en el mismo sitio destaca el recuerdo del capitán Darman de la muerte de 
El espacio novelesco y la descripción en Beltenebros, de Antonio Muñoz Molina

Walter asesinado a tiros. En la misma habitación ocurrió el encuentro de Darman con el joven español, Luque, que hacía de enlace para los correos que llegaban del Este, emisario de otros, que no iban a los aeropuertos ni a los hoteles. En esta habitación se produjo la entrega de la maleta que llevaba y también allí le dio las instrucciones de viajar al día siguiente a Madrid vía Roma para encargarse del asunto Andrade. Él contribuyó a la destrucción de la organización secreta en Madrid y fue el máximo responsable de entregar a sus miembros uno por uno a la policía. El narrador nos da a conocer la sensación negativa que consiste en la rabia y la irritación causados por la presencia de Luque de esta forma:

De modo que durante la visita del torpe enviado, ese Luque, no había sentido verdadera rabia ni verdadera piedad, únicamente la irritación física de no estar solo en una habitación tan estrecha, una molestia intensa, pero de segundo orden, semejante a la de un picor en la piel (Muñoz Molina, 1990: 38).

En la misma habitación del hotel de Florencia destaca el recuerdo de la ejecución a tiros de Walter a manos del capitán Darman en uno de los arrabales de Madrid, junto a un descampado de malezas. La correlación del protagonista con los espacios abiertos y cerrados, por el tiempo que pasa entre los aeropuertos y hoteles en diferentes ciudades de Europa, le hace imaginar que su vida se parezca a la de un monje retirado en un monasterio lejos del mundo:

había terminado por recluirme en los hoteles y en los aeropuertos como quien se retira a un monasterio [...] Yo era nadie, un muerto prematuro que todavía no sabe que lo es, una sombra que cruzaba ciudades y ocupaba en los hoteles habitaciones desiertas (Muñoz Molina; 1990: 14- 15 y 61).

En definitiva, en esta obra hemos visto una variedad de espacios cerrados como habitaciones tanto de hoteles como de casas particulares o locales de ocio, como la boîte Tabú, que forman parte de los hechos narrativos ocurridos a lo largo de dos días. No obstante, quizá los espacios más significativos en la novela analizada son el club nocturno de la boîte Tabú y el cine Universal, en el mismo sitio se vuelcan las confesiones más íntimas de los personajes. También allí tiene lugar el desenlace de la novela con la muerte del comisario Ugarte. «La bajada a la boîte, en la que hay espectáculos de tipo erótico, es la bajada a los infiernos que el héroe tiene que cumplir para realizar su tarea» (Díaz Navarro, 1998: 39). 


\subsection{El espacio móvil y su función en Beltenebros}

En esta novela policiaca es destacable la trascendencia del espacio móvil por la forma que requieren los hechos narrados . En la narración este tipo de espacio tiene una función muy importante que consiste en el desplazamiento de los personajes de un lugar a otro. Así que en esta novela, dentro del espacio urbano de la ciudad de Madrid u otras ciudades como Florencia, destacan dos espacios móviles: los taxis y los aviones que resultan necesarios por el género literario de suspense e intriga que aborda el escritor español.

La ciudad de Madrid es vista desde el taxi que lleva al capitán Darman hasta el bar Corinto en el Paseo de las Delicias, donde está guardada la llave de la consigna de la estación de Atocha. El narrador nos describe la capital española con sus calles y plazas hasta llegar a Atocha, pasando por la Castellana, el edificio de Correos, la estatua blanca de Cibeles, los árboles del Paseo del Prado, las verjas del Botánico y el hotel Nacional. En la misma descripción del paisaje madrileño, el narrador deja en evidencia la ideología antifranquista de Darman:

Dejó de llover y vi la última luz del sol sobre los árboles y los edificios de la Castellana, una luz muy fría que detallaba contra el pálido azul en lo más alto del edificio de Correos, donde ondeaba una bandera que siguió pareciéndome intrusa y enemiga, recién plantada allí por los usurpadores. [...] Y al final los rumorosos árboles del Paseo del Prado y las verjas del Botánico, el hotel que ahora se llamaba Nacional (Muñoz Molina, 1990: 68).

Desde el mismo espacio móvil que tiene la función de contraste entre un lugar y otro, a través de otro recorrido del protagonista de la estación de Atocha hasta la boîte Tabú, el escritor nos presenta otro panorama del centro de Madrid atravesando la Puerta del Sol y algunas de sus calles importantes como la Gran Vía y Valverde. Al pasar cerca de la Dirección General de Seguridad, el capitán Darman recuerda la huida de Andrade de una de las celdas de su cárcel. Asimismo llega a imaginar al comisario Ugarte mirando de alguna desde las ventanillas de los pisos superiores de este edificio, como solía hacerlo espiando los espectáculos de Rebeca Osorio desde el único palco reservado para él en la boîte Tabú. De igual forma, llega a la conclusión de que Ugarte sabe lo del asesinato de Andrade a manos de Luque:

El taxi había cruzado la Gran Vía y se internaba a ahora en una calle que me pereció la de Valverde. Decidí cuando encontrara a la muchacha no le contaría la muerte de Andrade: que siguiera esperándolo durante algún tiempo, hasta que el olvido la cansara (Muñoz Molina, 1990: 210). 
El espacio novelesco y la descripción en Beltenebros, de Antonio Muñoz Molina

En el mismo espacio móvil, Darman recuerda la muerte horrible de Andrade y su cadáver tirado en la oscuridad cerca de aquel hospital abandonado. A su vez, el escritor utiliza el cierre de los ojos y la distancia, a través de la velocidad del taxi, como una forma para cortar y frenar los recuerdos que vienen a la mente de Darman:

Le pedí al taxista que se fuera más de prisa, como si la distancia me pudiera salvar del acuciante recuerdo. Igual que quien no puede dormir y oye rumores de amenaza y aprieta los párpados hundiéndose debajo de las sábanas, yo cerraba los ojos porque me daban vértigo las rápidas luces de las calles (Muñoz Molina, 1990: 210).

También, entre los espacios móviles en la novela destaca el coche que lleva al capitán Darman del aeropuerto de Florencia hasta el Hotel Parigi, y desde esta perspectiva móvil, el narrador nos describe la ciudad utilizando un lenguaje que es, en muchos casos, rítmico y sugestivo del andar del coche, enumerándose calles, esquinas y semáforos:

Pero seguí inmóvil y guardando silencio en el asiento posterior (del coche), mirando calles oscuras y esquinas de barrios deshabitados, semáforos en ámbar que parpadeaban para nadie. La ciudad era igual a cualquier otra de Inglaterra o de Francia, una de esas ciudades que después del anochecer abandonan sus calles a los automovilistas que las cruzan viniendo desde muy lejos y ni siquiera la miran (Muñoz Molina, 1990: 23).

En esta escena, a través de los ojos del protagonista, el narrador nos describe la ciudad fantasma de Florencia en horas muy tardías de la noche, con sus calles vacías y las personas en sus viviendas. Desde la óptica del capitán Darman la ciudad de Florencia, sobre todo de noche y en la oscuridad, parece a otras ciudades de Francia o Inglaterra, es decir, que en muchos sitios europeos la vida de la gente es muy parecida; la gente suele acostarse pronto y no estar en vela hasta las tantas de la noche.

Entre los espacios móviles de esta novela destaca el taxi que lleva a Darman y Luque desde la Plaza de la catedral, en la ciudad de Florencia, hasta la casa donde estuvieron reunidos con Bernal. Era uno de los maltratados palacios italianos, que tenía sobre el portal dos banderas inclinadas, una roja y otra italiana, estaba situado en uno de los barrios grises de la ciudad, «El coche abandonó otra vez el centro de la ciudad y las proximidades brumosas del río y se adentraba en grises barrios de aire neutro a los que la nieve no había llegado aún» (Muñoz Molina 1990: 46). Esta casa fue el escenario del encuentro entre Darman y Bernal, ex compañero de la guerra, donde le explica la traición de Andrade entregando a sus compañeros de Madrid, uno a uno, a la policía española. También le cuenta la supuesta detención y huida de éste 
de un furgón delante la Dirección de Seguridad Nacional. De tal forma, este espacio cerrado tiene la función, por la bandera roja (símbolo del comunismo), de revelar la identidad y la ideología de Darmán y su organización antifranquista. Así lo afirma Bobes Naves, cuando señala que el espacio en la novela se utiliza como, «un signo que remite a la situación de los personajes, a sus modos de pensar y de conducirse, y además como un elemento estructural que permite la construcción de la sintaxis narrativa» (1985: 207).

Del mismo modo, cabe señalar que los aviones como espacios móviles forman parte de la construcción del espacio novelesco de esta obra, por el tipo de trabajo del capitán Darman que requiere ocultación y una cierta discreción, viajando de noche y en total oscuridad. El protagonista nos informa que nunca llega a conocer las ciudades en las que le encargan cumplir sus misiones clandestinas. De tal forma, que sólo llega a conocerlas desde el avión viendo sus luces, «yo casi nunca veía las ciudades a las que viajaba, sólo sus luces desde el cielo y sus nombres en los indicadores luminosos» (Muñoz Molina, 1990: 15). El motivo de no conocer bien estas ciudades es el poco tiempo que solía estar allí o que eran, solamente, unas ciudades de tránsito.

A través de los recuerdos de la guerra desde el punto de vista del protagonista los aviones en aquellos tiempos eran sitios muy inseguros como se observa en sus palabras, mientras está esperando en el aeropuerto de Florencia, «que tal vez aún estaba a tiempo de decirle al conductor que volviera a llevarme al aeropuerto, al refugio inseguro de aquel avión cuyas hélices resplandecían y vibraban como en los vuelos secretos de la guerra» (Muñoz Molina, 1990: 23).

En la misma línea podemos subrayar que Antonio Muñoz Molina es un escritor que no ha experimentado la guerra civil personalmente como otros escritores de la generación del medio siglo por ejemplo, solamente, llega a conocer sus malas consecuencias en otras personas de lejos y de una forma indirecta. «Igual que en sus otras novelas (Beatus Ille, El jinete polaco, El invierno en Lisboa), es evidente una repercusión lejana de la guerra civil, como si el autor quisiera conformarse con la carga posbélica del asunto» (Krc, 2009: 68).

\section{La descripción y su función en Beltenebros}

En esta novela, la descripción es uno de los procedimientos empleados por el autor para crear una atmósfera vinculada a los entes ficticios. En cuanto a sus funciones $^{4}$ en esta obra son varias y se distinguen una de la otra según el papel que tiene en

\footnotetext{
${ }^{4}$ En este sentido López-Landy señala que al describir los lugares que mejor reflejan el carácter de los personajes, el narrador suele hacer patente que lo descrito importa más por su función novelesca, creadora de una atmósfera, que por el interés intrínseco de los objetos. Principalmente los detalles
} 
la narración. Entre estas funciones destacan: la descripción informativa, explicativa, representativa, expresiva y decorativa.

Es de notar que la descripción informativa se considera como una de las funciones más importantes de la descripción por el papel que juega en la obra narrativa, que consiste en presentar al lector toda la información necesaria para seguir el hilo de la narración. En la escena del asesinato de Andrade a manos de Luque el escritor emplea este tipo de descripción para dar a conocer al lector todo sobre la manera y el tipo de arma usada en la muerte de Andrade. En algunos casos, a través de los elementos auditivos, visuales y olfativos que se presentan como partes inseparables de una atmósfera única; el lenguaje llega a ser poético como en la siguiente cita:

La detonación retumbó como el trueno de una tempestad bajo las bóvedas de un mar subterráneo, dilatándose sucesivamente hacia lo más hondo de las estancias vacías. No fue un disparo de pistola, sino de un arma más potente y más cruel que fulminó a Andrade igual que un rayo. Aturdido, temblando, con los tímpanos como atravesados por un dolor de agujas, todavía no me acerqué a él. Oía el gorgoteo último de su respiración y lo veía removerse en lentas convulsiones sobre losas donde estaba creciendo la mancha plana de sangre (Muñoz Molina, 1990: 202).

El lugar del asesinato de Andrade fue uno de los pasillos de un hospital abandonado de Madrid. Este sitio oscuro y solitario tuvo una correlación muy fuerte con el protagonista y, aparte de dejar una sensación demasiado negativa en el alma del capitán Darman, también lo hizo sentir muy mal, mientras estaba ante el cadáver sin la posibilidad de poder ayudarle o salvar su vida a tiempo:

que estaba muerto, boca arriba, con los ojos cerrados, tirado con un coágulo negro en el vientre en medio de la oscuridad helada y desierta de aquel hospital donde era posible que tardaran mucho en encontrarlo. Sentí que saber que estaba allí y que tal vez amanecería rígido y sólo en la misma postura en que lo paralizó la muerte era una última profanación que también a mí me envilecía (Muñoz Molina, 1990: 210).

En relación con la descripción representativa en la novela que estamos analizando podemos destacar la agonía y el sufrimiento de Andrade después de ser disparado a manos de Luque. En los detalles descriptivos el escritor nos ofrece, a través de la óptica del narrador en primera persona, el dolor, el sufrimiento de Andrade y la impotencia del capitán Darman al quedarse con las manos cruzadas sin hacer nada:

descriptivos crean un ambiente afín con las emociones de los personajes, revelador de las situaciones y escenas que acontecen (1979: 181). 
No quería mirarlo. Me tocó el hombro y yo seguí viendo la agonía de Andrade que se arañaba con las dos manos la desgarradura del vientre. Me arrodillé junto a él, y el otro me siguió, llamándome, diciéndome otra vez capitán. [...] Andrade me miraba con sus ojos escarchados por la cercanía de la muerte, y movía la cabeza y se palpaba las ingles espesamente enlodadas de sangre, y cuando curvó los labios para decir una palabra brotó de ellos un coágulo negro que se derramó como un vómito sobre su barbilla. Me quité la gabardina y se la puse doblada bajo su nuca, hablándole, pero ya no me oía (Muñoz Molina, 1990: 202).

Creo que en esta parte el novelista hace coincidir el mundo de las actitudes y los sentimientos con el de los espacios. Así, hemos visto como el capitán Darman, un asesino frío, calculador y verdugo sin escrúpulos, compadece como una persona humana en el sentido de compartir el sufrimiento y el dolor con su víctima.

En lo que respecta a la descripción expresiva, es aquella en la que el escritor puede expresar el estado de los personajes, sea social o psicológico, y sus valores a través de la descripción de la naturaleza o el ambiente en el que viven y se mueven. También por medio de esta descripción el escritor expresa los pensamientos y sentimientos de los personajes pero sin profundizar demasiado en el interior de ellos:

En el escenario, por encima de las cabezas opacas y los rostros azules, cantaba una mujer gorda, con tacones muy altos, con vestido largo de reflejos metálicos que tenía en el costado una abertura singularmente obscena. [...] El pianista parecía un profesor abrumado por una vejez sin dignidad. [...] Yo bebía y escuchaba risas contenidas y murmullos a mi alrededor y me iba envolviendo una lenta sensación de absurdo que agravaban la infamia del alcohol y las sonrisas codiciosas y adúlteras de los hombres vestidos de oscuro que en las mesas próximas fumaban y bebían junto a mujeres muy pintadas y enredaban como casualmente los dedos en sus manos (Muñoz Molina, 1990: 103).

Por medio de la descripción explicativa el escritor quiere explicar y dejar en evidencia el motivo de la actitud antifranquista adoptada por parte del capitán Darman. De cierta manera, veinte años más tarde ven a los falangistas como enemigos e intrusos que han usurpado el poder de las manos de la izquierda, que gobernaba España antes de la Guerra Civil. Esta actitud se observa claramente en las siguientes palabras del narrador:

Dejó de llover y vi la última luz del sol sobre los árboles y los edificios de la Castellana, una luz muy fría que detallaba contra el pálido azul en lo más alto del edificio de Correos, donde ondeaba una bandera que siguió pareciéndome intrusa y enemiga, recién plantada 
El espacio novelesco y la descripción en Beltenebros, de Antonio Muñoz Molina

allí por los usurpadores. [...] Y al final los rumorosos árboles del Paseo del Prado y las verjas del Botánico, el hotel que ahora se llamaba Nacional (Muñoz Molina, 1990: 68).

Por último, destaca la función decorativa, que es un tipo de la descripción puramente ornamental. A través de la cual el escritor crea y deja en el lector de la obra una buena impresión, que aparte de presentar una escena o un hecho real, también deja otra impresión sensual y poética. Así es de notar este tipo de descripción que no ofrece el narrador en las siguientes pinceladas de la entrada del Hotel Parigi en Florencia:

En el vestíbulo del hotel había columnas de granito y altos espejos que duplicaban palmeras de plástico. El ascensor, tapizado de un rojo sofocante, subía muy despacio, y en las bóvedas de los pasillos había pinturas mitológicas (Muñoz Molina, 1990: 25).

En definitiva, cabe señalar que en el espacio urbano de la gran ciudad de Madrid, la mirada de Muñoz Molina se detiene y descubre los detalles. La gran estación de Atocha, la Puerta del Sol, bares, cafetería, y otros espacios interiores merecen una descripción costumbrista. «Bien es verdad que muchos de los objetos descritos forman parte de la idiosincrasia del personaje, mientras que otros pretenden incidir, con su iniciación, en los misterios de la gran ciudad» (Popeanga, 2009: 294), como el laberinto o túnel que comunica el club nocturno con el Universal Cinema. Podemos observar cómo el lujo detallista va desde la descripción de interiores de la estación de Atocha y la entrada del hotel Nacional donde fue alojado el capitán Darman, hasta los motivos más humildes, incluso lúgubres y sórdidos del interior del almacén helado y abandonado cerca de la estación de trenes. La descripción de algunos objetos sirve para identificar a los personajes y marcar sus diferencias sociales. Esto se nota en la descripción del tipo de ropa, zapatos, el tabaco inglés que fuma Andrade, pagado todo por su compañera sentimental Rebeca Osorio. También el tipo de ropa y alojamiento en hoteles muy caros donde solía instalarse el capitán Darman, financiados todos sus gastos por su organización clandestina.

También apuntamos que en esta novela, cuando se refiere a los exteriores o interiores, se nota en el autor un deseo de transmitir el abandono y el descuido de un sitio determinado y esto queda más que claro ya en uno de los capítulos de la novela, como puede verse en la siguiente descripción del almacén de Atocha:

Era un almacén con las paredes de ladrillo rojo y desnudo y el suelo de madera, y desde lejos parecía una torre abandonada y sola a la orilla de un río, más alta que las últimas tapias de la estación y que los haces de cables tendidos sobre las vías, cúbica y ciega, en- 
negrecida desde los tiempos de las locomotoras de carbón, con puertas y ventanas como tachadas por maderas en aspas que fueron hincadas a los marcos con una seña definitiva de clausura (Muñoz Molina, 1990: 8).

A través de las anteriores pinceladas el escritor describe de una forma minuciosa y selectiva este almacén, donde está escondido, momentáneamente, uno de los personajes de la novela. En el mismo sitio transcurren algunos episodios del relato, como el encuentro entre la bailarina Rebeca Osorio y el comisario Ugarte. Durante este encuentro los dos son espiados desde detrás de la cortina de la ventana por el capitán Darman, mientras esperaba al supuesto traidor que nunca llegó a aparecer en el lugar. También, uno de los rasgos destacados que ha empleado Antonio Molina en la descripción de este espacio los colores: el rojo, el negro y las formas cúbicas para dar una idea cinematográfica del lamentable estado de este lugar cerrado y clausurado definitivamente, que sus puertas y ventanas por fuera protegidos con maderas en aspa hincadas a los marcos. El escritor realiza la descripción de una forma tan detallada desde fuera hacia dentro para subrayar que en este sitio no queda ninguna señal de vida. La única razón por la cual puede haber alguna señal de vida en este sitio sería la presencia de una persona marginada, un sin techo o alguien huyendo de la ley por el motivo que fuese.

\section{Conclusiones}

En esta novela concluimos, que es destacable la coherencia entre los elementos narrativos como, por ejemplo, en la representación del espacio novelesco. De tal modo, los sitios en los que ocurren los sucesos más relevantes son adecuados a una situación de misterio, suspense e intriga. También, es de notar la correlación trascendental y la estrecha vinculación entre el espacio novelesco y los personajes. El comienzo de la acción tuvo lugar en el almacén abandonado de Atocha y el desenlace final, con la muerte de Ugarte, en el Universal Cinema, refugio de la organización clandestina y antifranquista. Aunque la obra está ambientada en el marco urbano de Madrid y otras ciudades europeas, como Florencia, muchos de los hechos narrados ocurren en un espacio con una disposición laboral nocturna, la boîte Tabú entre otros. Según Marta Ferrari, la intención mimética del escritor, tras crear un tipo de atmósfera de misterio y suspense, consiste en dar al espacio una ambientación típica, lánguida, opaca y oscura (2000: 205). Así que, a lo largo de la narración damos cuenta de que todos los sucesos relevantes ocurren de noche en plena oscuridad. De hecho, la oscuridad es un elemento primordial que constituye la atmósfera idónea para este tipo de narración. 
En cuanto a la evolución espacial en Beltenebros, el escritor utiliza aeropuertos, estaciones de trenes, puntos de tránsito o de paso, y lugares abandonados que muestran la encrucijada filosófica que mantiene el capitán Darman. Entre las funciones del espacio novelesco, aparte de servir como elemento contribuyente a la organización del material narrativo, también funciona como marco de referencia y signo del pasado irrecuperable.

En lo que respecta a la descripción, en esta novela ha sido como uno de los procedimientos empleados por el autor para crear una atmósfera vinculada a los entes ficticios. En ella, los elementos sensoriales como lo visual y auditivo, y en especial el contraste claridad y oscuridad, silencio y ruido funcionaron como vínculo unificador entre personajes, ambientes y locales, en un espacio perceptible como totalidad homogénea. También el uso de los colores: el rojo y el negro y las formas cúbicas tuvo la función de dar una idea cinematográfica al sitio descrito o verosimilitud al hecho narrado. Así que las descripciones de individuos, objetos o paisajes y casas, existieron no sólo por su función reveladora del carácter de los personajes, sino también como elemento subordinado al proceso narrativo y al conflicto ideológico entre izquierda y derecha en la obra. Aunque es una novela policiaca, el escritor hace referencia, de una forma indirecta, a una etapa determinada en la vida de la sociedad española. La descripción sirve sobre todo para ambientar la acción y crear una atmósfera que haga más creíbles los hechos que se narran.

En definitiva, la descripción es una de las características de esta la novela, y no es únicamente ornamental sino actúa como un elemento esencial en la estructura de la narrativa. Su importancia consiste en la cohesión textual y su contribución al efecto de verosimilitud. Aparte de este rasgo, también destaca su función en la presentación de los personajes en un espacio y tiempo narrativo adecuados.

\section{Bibliografía}

Bajtín, Mijail, Teoría y estética de la novela, Madrid, Taurus, 1989.

Begines Hormigo, José Manuel, La teoría literaria de Antonio Muñoz Molina, Tesis Doctoral, Sevilla, Universidad de Sevilla, 2006.

Bobes Naves, María del Carmen, Teoría General de la novela, Semiología de La Regenta, Madrid, Gredos, 1985.

Bobes Naves, María del Carmen, La novela, Madrid, Síntesis, 1993.

Castagnino, Raúl Héctor, El análisis literario, Buenos Aires, Editorial Nova, 1969.

Díaz Navarro, Epicteto, «Ficción, suspense y autobiografía en Beltenebros de Antonio Muñoz Molina», Revista de de Lengua y Literatura Españolas, № 1, 1998, págs. 36-47. 
Ferrari, Marta Beatriz, «Tradición literaria y cinematográfica en Beltenebros de Antonio Muñoz Molina», CELEHIS - Revista del Centro de Letras Hispanoamericanas Año IX, Nº12. Mar del Plata, 2000, págs. 195-212.

Garrido Domínguez, Antonio, El texto narrativo, Madrid, Síntesis, 1993.

Genette, Gérard, Figure II, Paris, Seuil, 1972.

Hamon, Philipe, Qu'est-ce qu'une description, in Poétique 12. Paris, Seuil, 1972 .

Krc, Eduard, «La visión espaciotemporal en Antonio Muñoz Molina y Javier Tomeo», Estudes Romanes de Brno 30, 2009, 2, págs. 65-73.

López-Landy, Ricardo, El espacio novelesco en la obra de Galdós, Madrid, Ediciones Cultura Hispánica, 1979.

Muñoz Molina, Antonio, Beltenebros, Barcelona, Seix Barral, 1990.

Muñoz Molina, Antonio, La huella de unas palabras: Antología de Antonio Muñoz Molina, Barcelona, Espasa Calpe, 1999.

Popeanga, Eugenia «Modelos urbanos de serie: Los misterios de Madrid de Antonio Muñoz Molina», Cuadernos de Filología Alemana 2009, anejo I, 287-297.

Ricardoud, Jean, Problémas du nouveau roman, Paris, Seuil, 1967.

Terenci Moix, El peso de la paja-Memorias- El cine de los sábados, Barcelona, Plaza Janes, 1990.

Vázquez Naveira, Marta María, Texto literario y texto fílmico. Análisis comparativo-textual de El invierno en Lisboa, Beltenebros y Plenilunio de Antonio Muñoz Molina, Tesis Doctoral, La Coruña, Universidad de A Coruña, 2014.

Wellek, René y Warren, Austin, Teoría literaria, Madrid, Gredos, 1985. 